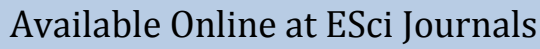 \\ International Journal of Phytopathology \\ ISSN: 2305-106X (Online), 2306-1650 (Print)
} http://www.escijournals.net/phytopathology

\section{A NEW ACCURATE GENOTYPING HRM METHOD FOR ALTERNARIA SPECIES RELATED TO FRUIT ROT DISEASES OF APPLE AND POMEGRANATE}

aAntonios Zambounis, bAliki Xanthopoulou, cGeorge Karaoglanidis, a,bAthanasios Tsaftaris, bPanagiotis Madesis*

${ }^{a}$ Laboratory of Genetics and Plant Breeding, School of Agriculture, Forestry and Natural Environment, Aristotle

University of Thessaloniki, P.O. Box 261, Thessaloniki GR-54124, Greece.

$\boldsymbol{b}$ Institute of Applied Biosciences, CERTH, Thermi, Thessaloniki, Greece.

${ }^{c}$ Laboratory of Plant Pathology, School of Agriculture, Forestry and Natural Environment, Aristotle University of

Thessaloniki, P.O. Box 261, Thessaloniki GR-54124, Greece.

\section{A B S T R A C T}

Alternaria core rot and Alternaria black heart rot of apple and pomegranate fruit, respectively, are major pre- and postharvest diseases worldwide. However, it is very difficult to differentiate the rot related Alternaria species in the Alternaria complex as they are not always correlate to species-groups based upon morphological characteristics and due to the limited genetic variation these species exhibit among each other. Therefore, it is crucial to exploit novel assays towards the accurate identification and differentiation of these Alternaria species. We have developed, a realtime PCR assay [using species specific primers targeting the endopolygalacturonase (EndoPG) gene] combined with a high-resolution melting (HRM) curve analysis for discrimination of the 14 single nucleotide polymorphisms (SNPs)based Alternaria haplotypes, which were assigned based on the aligned sequence profiles of 138 Alternaria spp. strains previously isolated from apple and pomegranate rotted fruit. This analysis specifically generated 14 unique HRM curve haplotype profiles among the Alternaria complex species tested. The results showed that HRM curve analysis allows the rapid and adequate identification and genotyping of the three Alternaria species (A. alternata, A. tenuissima and $A$. arborescens) responsible mostly for the apple and pomegranate fruit rot diseases.
\end{abstract}

Keywords: Alternaria-species complex; apple fruit core rot; endopolygalacturonase gene; HRM genotyping; pomegranate fruit black heart rot.

\section{INTRODUCTION}

Alternaria core rot of apple fruit (Malus domestica) is considered as the most severe postharvest disease of apples occurring in several places of the world, including Greece (Gao et al., 2013; Ntasiou et al., 2015). The disease initiates during bloom from the loculus and spreads into the fruit mesoderm leading finally to either a dry or wet core rot (Shtienberg, 2012). External symptoms are only evident after fruit harvest, while during storage the rot still progresses and may be observed on the fruit epidermis after several months (Shtienberg, 2012). Additionally, pomegranate (Punica granatum L.) is a rapidly expanding crop throughout the world because of the fruit great nutritional value and human diet benefits (Gil et al., 2000). As apple fruits, pomegranate fruits suffer

\footnotetext{
* Corresponding Author:

Email: pmadesis@certh.gr

(C) 2015 ESci Journals Publishing. All rights reserved.
}

also from the so called Alternaria black heart disease that occurs both as a pre- or postharvest disease, and that has been found in several countries worldwide (Ezra et al., 2015; Michailides et al., 2008). Pathogen may penetrate either through injuries of fruit exocarp or during the blooming period, and remain latent until the onset of fruit maturation, becoming evident during storage (Palou et al., 2013). Alternaria decays not only reduce the yield, but may also deteriorate the quality of the fresh or processed fruit because of the production of mycotoxins. Mycotoxins could be quite dangerous if contaminated apples or pomegranates are designated to processing, especially for juices and baby foods production, since they have mutagenic and carcinogenic effects (Ostry, 2008).

Despite preliminary studies, based mainly on morphological evidences, suggested A. alternata as the causal agent of the disease both in apples and pomegranates, more recent molecular surveys indicated 
that several other small-spored Alternaria species such as $A$. tenuissima, $A$. arborescens and $A$. infectoria might be the causal agents of the disease (Gao et al., 2013; Kou et al., 2014). Recently, it was shown that Alternaria species obtained from in stored apple fruits which depicted core rot disease symptoms in Greece, were recognized as $A$. tenuissima or $A$. arborescens based on the sequencing of regions of endopolygalacturonase $(E n d o P G)$ gene (Ntasiou et al., 2015). Similarly, in another study aiming to identify the agents of pre- and postharvest rots of pomegranate fruit in Greece and Cyprus, it was shown that black heart rots of pomegranate fruit were caused by A. alternata, $A$. tenuissima and A. arborescens (Kanetis et al., 2015).

Recently, molecular surveys revealed a wealth of nonmonophyletic genera both within the Alternaria complex and Alternaria species lineages, which do not always being associated to species-groups based upon morphological features (Woudenberg et al., 2013). This diversity in Alternaria complex suggests that both in apples and pomegranate a number of distinct Alternaria species lineages, being associated with small-spored Alternaria, encompasses this rot disease. Thus, in order to understand and solve the challenging issue of differentiating Alternaria rot species, the development of precise and efficient molecular fungal diagnostics is of paramount importance (Woudenberg et al., 2013).

A novel molecular method, termed high-resolution melting (HRM), has been extensively used for DNA genotyping applications (Reed and Wittwer, 2004). According to this technique, the rate of double-stranded DNA dissociation is measured under gradually increasing temperatures (Reed and Wittwer, 2004). The advantage of this technique is actually based on a suitable fluorescent dye homogenously intercalated into the DNA. Upon the melting of the PCR products, the rate of dissociation is relevant with various thermodynamic properties of these products (Ganopoulos et al., 2012). Consequently, these thermodynamic properties of the PCR products trigger specific changes in fluorescence measurements and alter the shape of melting curve profiles during this dissociation. HRM has already been employed in the successful identification and differentiation of other fungal species, while at the same time helps eliminating contamination risks during the whole process (for review see Zambounis et al., 2015).

The EndoPG gene has been previously employed in the delineation of the closely related species within the Alternaria complex and was used for pathogen identification and phylogenetics (Hong et al., 2005;
Andrew et al., 2009). Therefore, based on the sequencing data obtained from two previous surveys (Kanetis et al., 2015; Ntasiou et al., 2015), the scope of this survey was to establish HRM technique as method of choice for the accurate and rapid discrimination of Alternaria complex species associated with apple and pomegranate fruit rots.

\section{MATERIALS AND METHODS}

Fungal isolates and sequences: In the present study, we used the genomic DNA of 138 fungal isolates, obtained from apples and pomegranate fruit showing decay symptoms and accurately identified at their Alternaria species level (A. alternata, A. tenuissima and $A$. arborescens), by a combination of molecular (direct sequencing approaches) and morphological evidences (Kanetis et al., 2015; Ntasiou et al., 2015). We also retrieved from NCBI the corresponding 138 sequences including: i) $67 \mathrm{~A}$. tenuissima and $8 \mathrm{~A}$. arborescens sequences from apples (GenBank Accession numbers: LK054418-LK054484 and LK054410-LK054417, respectively), and ii)30 A. alternata, 19 A. tenuissima and 14 A. arborescens strains from pomegranate (GenBank Accession numbers: KP789517-789546, KP789498KP789516 and KP789484-KP78947, respectively) (Table 1). These related amplicons have been previously obtained (Kanetis et al., 2015; Ntasiou et al., 2015) using the universal primers PG3 and PG2b (Andrew et al., 2009) targeting a region of the EndoPG gene.

Sequences alignment, haplotypes assignment and HRM analysis: The MUSCLE software (Edgar, 2004) inferred in the Geneious package (Drummond et al., 2009) was used for the alignment of the 138 Alternaria species sequences. We identified a fragment in the aligned homologous region, where adequate single nucleotide polymorphisms (SNPs) have been detected, permitting their clustering in unique SNPs-based Alternaria haplotypes (Table 1). Based on this alignment profile specific primers for the EndoPG gene, Alternaria_For (5' - CAACTTTGGACCTCTCTAGTCTGG -3') and Alternaria_Rev (5'- GTCTTTCCACCATTTCCACCCTT $3^{\prime}$ ) were manually designed; these primers were capable for amplifying a $199 \mathrm{bp}$ amplicon for all the 138 Alternaria species isolates. Two independent representative isolates of each Alternaria haplotype were analysed in HRM experiments.

HRM analysis, were performed on EndoPG PCR products obtained by the specific primers, in a final volume of 15 $\mu \mathrm{l}$ using the Rotor-Gene 6000 real-time 5P HRM PCR Thermocycler (Corbett Research, Sydney, Australia). 
We used an initial denaturing step of $95^{\circ} \mathrm{C}$ for $10 \mathrm{~min}$ followed by 35 cycles of $95^{\circ} \mathrm{C}$ for $5 \mathrm{~s}, 52^{\circ} \mathrm{C}$ for $15 \mathrm{~s}$ and $72^{\circ} \mathrm{C}$ for $10 \mathrm{~s}$, following be a final extension step of $72^{\circ} \mathrm{C}$ for 2 min. Before HRM, the products were denatured $\left(95^{\circ} \mathrm{C}\right.$ for $\left.5 \mathrm{~s}\right)$, and then annealed at $50^{\circ} \mathrm{C}$ for $30 \mathrm{~s}$ to randomly form DNA duplexes. HRM was performed as follows: premelting at the first appropriate temperature for $90 \mathrm{~s}$, and melting at a ramp of $10^{\circ} \mathrm{C}$ in an appropriate temperature range setting at $0.1^{\circ} \mathrm{C}$ increments every 2 s. End point fluorescence measurements were retrieved following the melting process by holding at $60^{\circ} \mathrm{C}$ for $5 \mathrm{~min}$ and for 5 cycles at $60^{\circ} \mathrm{C}$ for $20 \mathrm{~s}$, while fluorescence data being obtained at the end of each cycle step. The reaction mixture contained $20 \mathrm{ng}$ fungal DNA, 1X PCR buffer, $2.5 \mathrm{mM} \mathrm{MgCl}_{2}, 0.2 \mathrm{mM}$ dNTP, $300 \mathrm{nM}$ forward and reverse primers, $1.5 \mathrm{mM}$ Syto9® green fluorescent nucleic acid stain, and 0.5 U Kapa Taq DNA polymerase (Kapa Nippon Genetics). Finally, each Alternaria haplotype profile was assigned as a genotype, and the average HRM genotype confidence percentages (GCPs) for each haplotype were applied according to Hewson et al., (2009). A GCP value of 100 implied an accurate genotype match. The correct sizes of all PCR amplicons were confirmed by agarose gel visualization.

\section{RESULTS AND DISCUSSION}

Taking into account that Alternaria core rot and black heart rot diseases represent major threats for apple and pomegranate fruit production, respectively, the application of innovative molecular diagnostic approaches is undoubtedly nowadays a crucial challenge
(Ntasiou et al., 2015). Moreover, considering the well documented taxonomic problems and the complexity of this collective group at species level with associated small-spored Alternaria, rapid and accurate molecular techniques should contribute towards the precise identification of Alternaria species being involved in this disease (Harteveld et al., 2013).

SNPs-based Alternaria complex haplotypes assignment: Alignment of the 138 sequences of Alternaria species EndoPG gene was performed using the MUSCLE software (Edgar, 2004); the overall identity was 99.4\% among these sequences. We identified various SNPs, even among the same species sequences, which were distributed in seven different positions along the $199 \mathrm{bp}$ in length amplicons (Supp Figure 1). Except point mutations in the above ungapped alignment, there were not observed any insertions or deletions (Supp Figure 1). Taking into account the alignment profile, 14 SNPsbased Alternaria complex haplotypes were assigned, from now on called simply as "haplotypes" (six for A. arborescens, five for $A$. tenuissima and three for $A$. alternata). The distribution of Alternaria spp. sequences among these 14 haplotypes and their hosts of origin are shown in Table 1.

The HRM analysis allow an accurate genotyping and differentiation of the Alternaria complex haplotypes: Specific primers were designed for the HRM analysis of the above Alternaria haplotypes; these primers amplified constantly an amplicon of $199 \mathrm{bp}$, which was harbouring the identified SNPs observed in the sequences alignment.

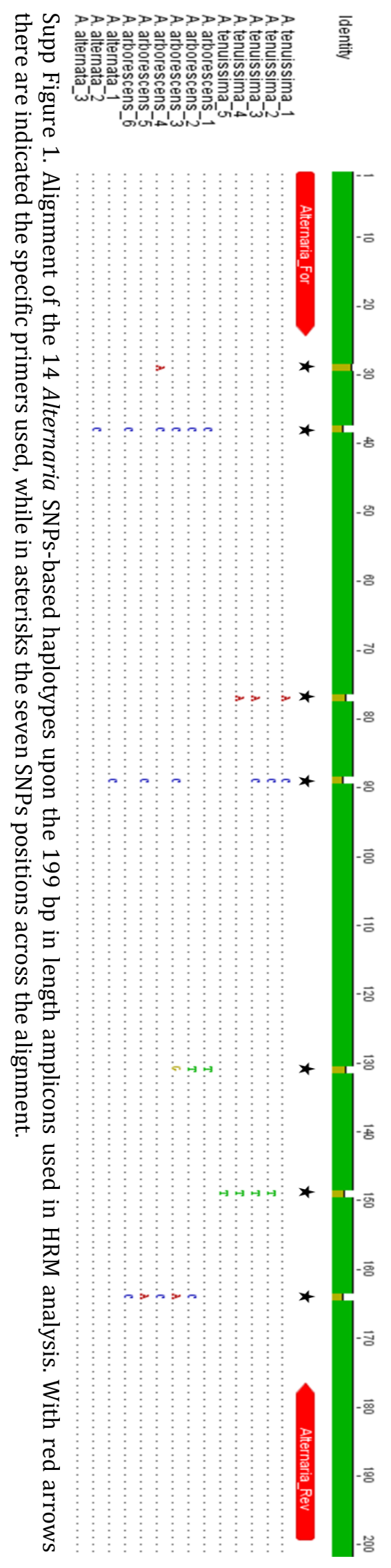


(a)

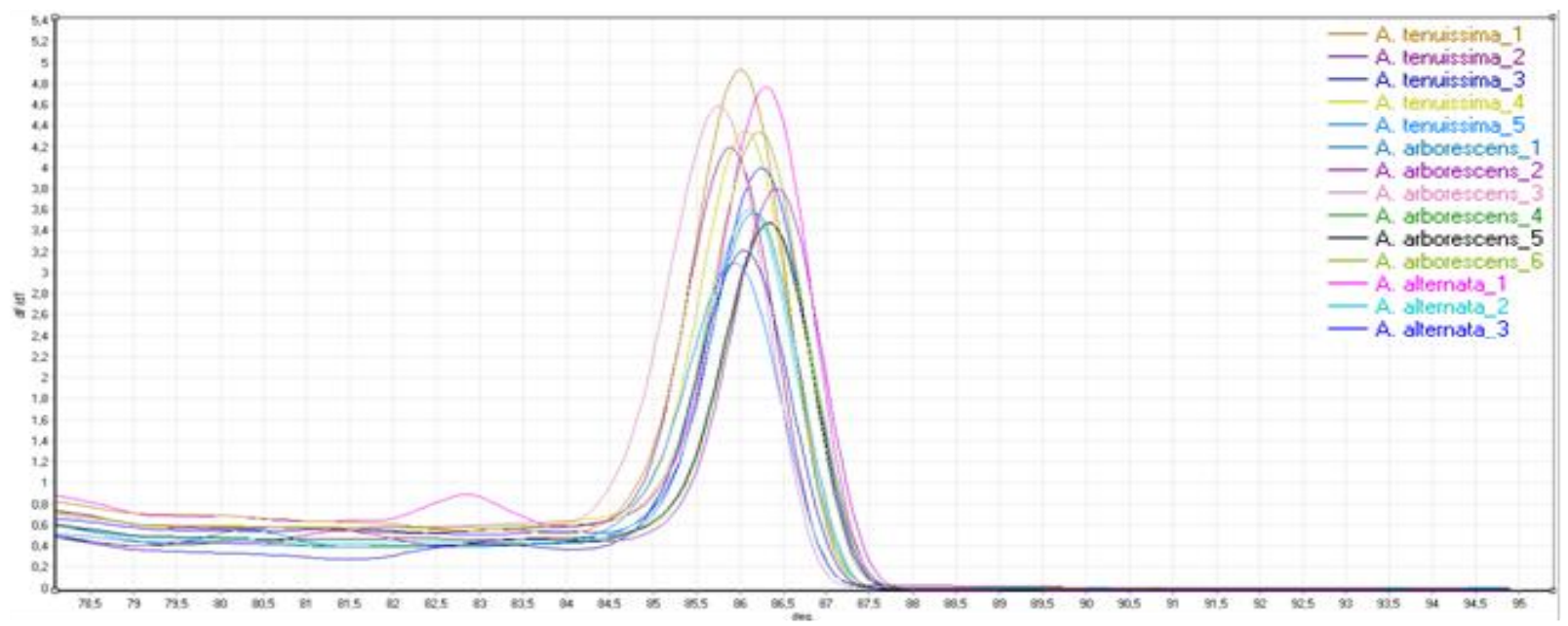

(a)

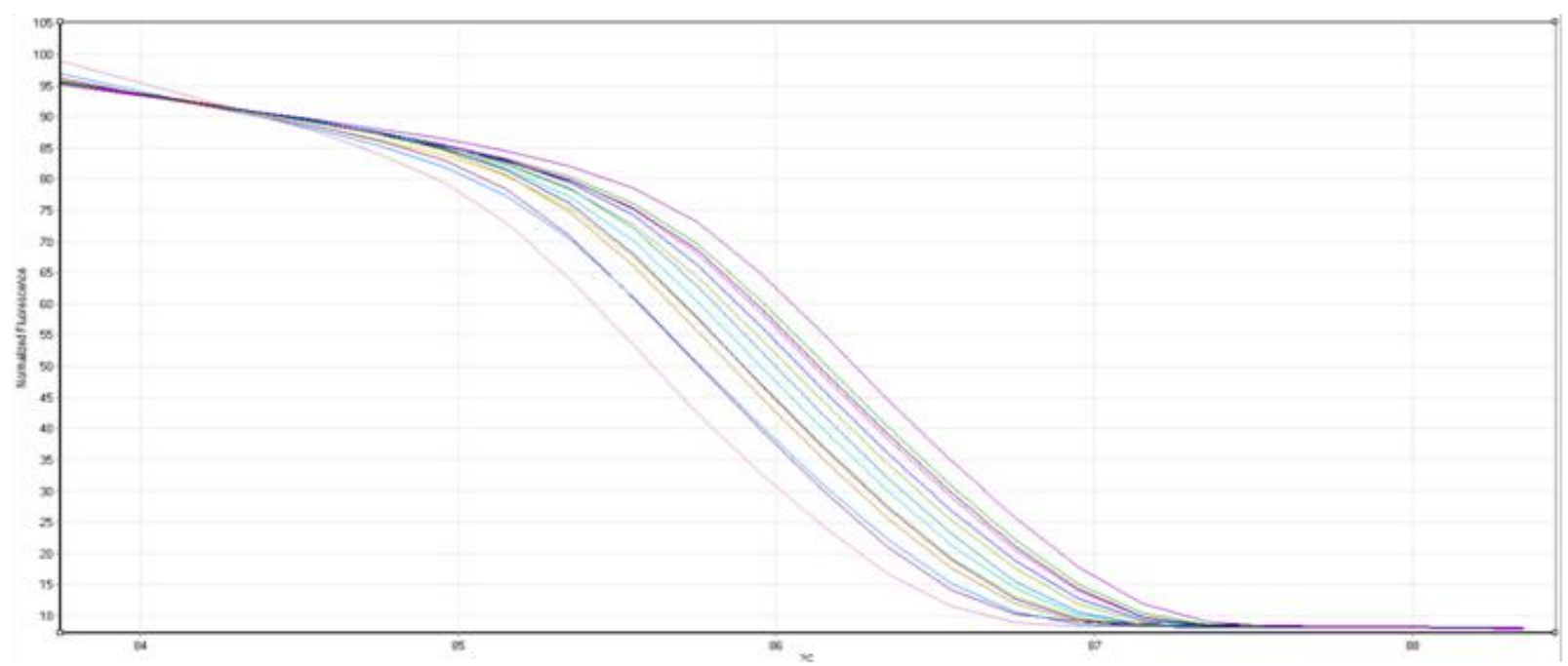

(a)

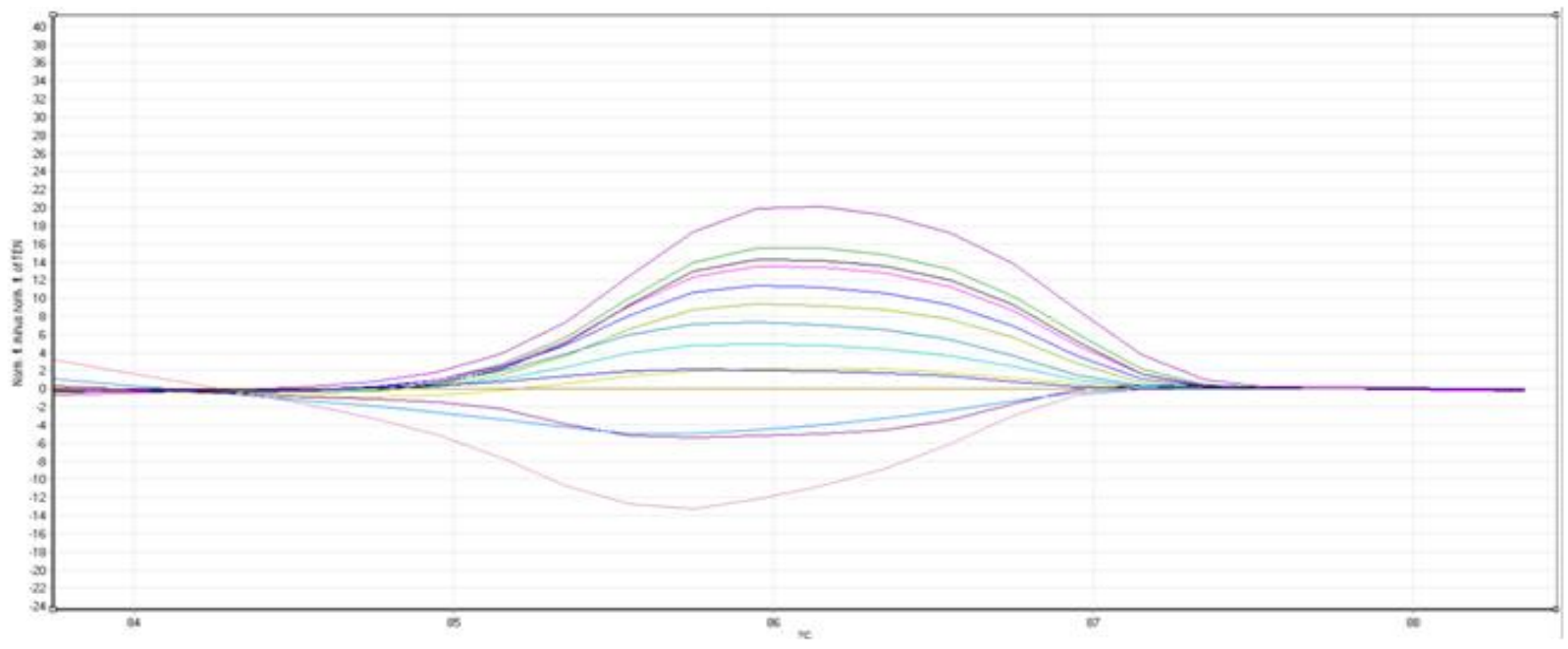

Figure 1. (a) EndoPG gene conventional HRM curves, (b) HRM profiles produced by the 14 Alternaria complex species haplotypes, (c) Alternaria haplotypes difference normalized graphs assigning 'A. tenuissima_1' haplotype as a normalized reference genotype. Identical genotypes were assigned using a cutoff GCP value of $95 \%$. 
Figure 1a depicts the results of Alternaria haplotypes conventional genotyping plots. Each genotype presented a unique peak, in a range from 81 to $85^{\circ} \mathrm{C}$ (data not shown). The different Alternaria strains tested, corresponding to each haplotype, generated distinctive normalized HRM profiles, facilitating the accurate identification of each haplotype. In general, the resolving efficiency of the data obtained is much higher than other similar conventional melting curve analysis, because the HRM curves efficiently differentiated amplicons even when they shared exactly the same Tm, because of curve shape as the result of the heterozygosis related effects (Liew et al., 2004).

In this study, we based the discrimination of 14
Alternaria haplotypes upon their informative HRM curve profiles (Figure 1b). Analysis of the EndoPG gene marker produced normalized HRM curves (Figure 1c), indicating that all of the haplotypes were efficiently distinguished from each other, despite the similarity of certain HRM profiles of some haplotypes (Figure 1b). We assigned the 'A. tenuissima_1' haplotype as a reference genotype, as this haplotype comprised the highest number of Alternaria spp. sequences tested in the present study (Table 1). The GCPs similarity values between this reference haplotype and the remaining ones (Table 2) indicated that EndoPG gene was a promising locus for identification and differentiation of the haplotypes sequences under investigation (Figure 1c).

Table 1. Alternaria species, SNPs-based haplotypes, number of isolates sequences assigned to each haplotype and their hosts of origin.

\begin{tabular}{cccc}
\hline $\begin{array}{c}\text { Alternaria species identified } \\
\text { according to previous studies }\end{array}$ & SNPs-based haplotypes & $\begin{array}{c}\text { Number of isolates sequences } \\
\text { assigned to haplotypes }\end{array}$ & Hosts of origin \\
\hline A. tenuissima & A. tenuissima_1 & 67 & apple \\
& A. tenuissima_2 & 2 & pomegranate \\
& A. tenuissima_3 & 11 & pomegranate \\
& pomegranate & pomegranate \\
\hline A. tenuissima_4 & Arborescens & 2 & apple \\
& A. tenuissima_5 & 4 & apple \\
& A. arborescens_1 & 6 & pomegranate \\
& A. arborescens_2 & 2 & pomegranate \\
& A. arborescens_4 & 2 & pomegranate \\
& A. arborescens_5 & 2 & pomegranate \\
\hline A. arborescens_6 & 4 & pomegranate \\
& A. alternata_1 & 6 & pomegranate \\
& A. alternata_2 & 22 & pomegranate \\
\hline
\end{tabular}

The GCPs values were employed as described previously (Hewson et al., 2009) using a cutoff value of $95 \%$ to assign an identical genotype. The highest GCP value (88.84) was observed between the 'A. tenuissima_3' and 'A. tenuissima_4' haplotypes both comprising isolates from pomegranate, while the lowest (0.02) was between 'A. arborescens_2' and 'A. arborescens_3' haplotypes which were considered distinctly different profiles, assigning isolates from apples and pomegranate, respectively. Furthermore, the ' $A$. tenuissima_1'haplotype, to which 67 A. tenuissima sequences from apples were assigned, depicted quite high GCPs among the other four $A$. tenuissima haplotypes (Table 2), implying that in principle differentiation of this haplotype was quite challenging against the other $A$. tenuissima haplotypes in the HRM analysis.
Overall, the 138 Alternaria sequences, which were previously classified in the three Alternaria species, were efficiently clustered in the 14 different haplotypes according to their SNPs homology profiles, possessing point mutations capable of revealing shape fluctuations in the respective HRM haplotype curves, even at their species level (Figure 1a). By this way, variations of haplotype sequences at a specific region of the EndoPG gene was translated into an informative and reproducible HRM curve genotyping analysis for the examined haplotypes (Figure 1b). In the present study we transferred direct DNA sequencing results previously acquired to discriminate Alternaria species to a more sensitive and precise HRM assay; this was exemplified by the successful genotyping of the 14 Alternaria haplotypes tested. 
Table 2. The average genotype confidence percentage values $( \pm 2.7)$ for the 14 Alternaria haplotypes, derived from the HRM analysis, using a ramp of $0.1{ }^{\circ} \mathrm{C}$.

\begin{tabular}{|c|c|c|c|c|c|c|c|c|c|c|c|c|c|c|}
\hline & 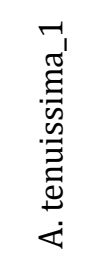 & 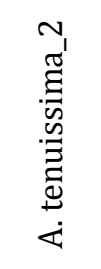 & 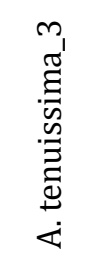 & 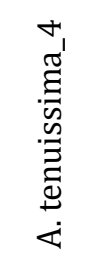 & 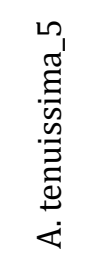 & 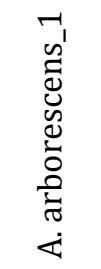 & 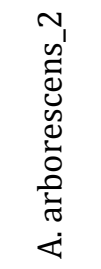 & 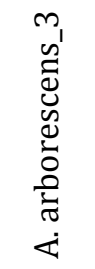 & 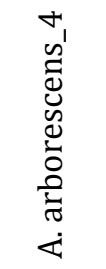 & 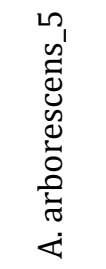 & 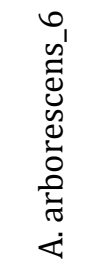 & 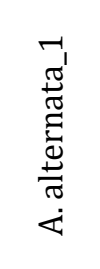 & 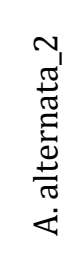 & 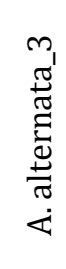 \\
\hline A. tenuissima_1 & 100 & - & - & - & - & - & - & - & - & - & - & - & - & - \\
\hline A. tenuissima_2 & 71.39 & 100 & - & - & - & - & - & - & - & - & - & - & - & - \\
\hline A. tenuissima_3 & 85.83 & 54.3 & 100 & - & - & - & - & - & - & - & - & - & - & - \\
\hline A. tenuissima_4 & 84.14 & 53.36 & 88.84 & 100 & - & - & - & - & - & - & - & - & - & - \\
\hline A. tenuissima_5 & 82.01 & 83.43 & 66.41 & 66.55 & 100 & - & - & - & - & - & - & - & - & - \\
\hline A. arborescens_1 & 58.98 & 19.02 & 75.73 & 77.22 & 27.53 & 100 & - & - & - & - & - & - & - & - \\
\hline A. arborescens_2 & 2.59 & 0.32 & 4.81 & 5.38 & 0.59 & 19.8 & 100 & - & - & - & - & - & - & - \\
\hline A. arborescens_3 & 24.25 & 61.09 & 14.62 & 14.77 & 55.79 & 3.16 & 0.02 & 100 & - & - & - & - & - & - \\
\hline A. arborescens_4 & 10.05 & 1.7 & 16.57 & 18.16 & 2.94 & 47.8 & 83.33 & 0.17 & 100 & - & - & - & - & - \\
\hline A. arborescens_5 & 13.3 & 2.42 & 21.28 & 23.26 & 4.16 & 56.29 & 74.17 & 0.38 & 88.47 & 100 & - & - & - & - \\
\hline A. arborescens_6 & 41.5 & 11.44 & 56.71 & 59.63 & 17.53 & 83.12 & 34.72 & 1.77 & 69.08 & 77.75 & 100 & - & - & - \\
\hline A. alternata_1 & 17.26 & 3.37 & 26.87 & 28.95 & 5.61 & 64.89 & 67.48 & 0.38 & 85.91 & 88.8 & 84.75 & 100 & - & - \\
\hline A. alternata_2 & 78.56 & 32.96 & 59.95 & 82.87 & 44.31 & 84.44 & 11.38 & 6.91 & 32.18 & 39.42 & 80.35 & 47.18 & 100 & - \\
\hline A. alternata_3 & 29.07 & 6.77 & 42.34 & 44.75 & 10.71 & 83.05 & 48.39 & 0.88 & 82.87 & 89.62 & 86.62 & 84.81 & 66.1 & 100 \\
\hline
\end{tabular}

Conclusively, this is the first survey according to our knowledge using the HRM technique aiming at differentiating the Alternaria species complex at species level. We demonstrate that this approach is both an accurate and a rapid molecular assay for the genotyping of the small-spored Alternaria species (A. alternata, $A$. tenuissima and $A$. arborescens), associated with apple and pomegranate fruit decays in Greece. Finally,this genotyping method could be used potentially to allocate even unknown Alternaria isolates to the HRM melting profiles of the tested species haplotypes.

\section{REFERENCES}

Andrew, M., Peever, T. L., Pryor, B. M., 2009. An expanded multilocus phylogeny does not resolve morphological species within the small-spored Alternaria species complex. Mycologia. 101:95-109.

Drummond. A.J., Ashton, B., Cheung, M., Heled, J.,
Kearse, M., Moir, R., Stones-Havas, S. Thierer, T., Wilson, A., 2009. Geneious v4.8, Available from http://www.geneious.com/

Edgar, R.C., 2004. MUSCLE: a multiple sequence alignment method with reduced time and space complexity. BMC Bioinformatics. 5:1-19.

Ezra, D., Kirshner, B., Hershcovich, M., Shtienberg, D., 2015. Heart rot of pomegranate: disease etiology and the events leading to 
development of symptoms. Plant Disease. doi: PDIS-0714-0707-RE.

Ganopoulos, I., Madesis, P., Zambounis, A., Tsaftaris, A., 2012. High-resolution melting analysis allowed fast and accurate closed-tube genotyping of Fusarium oxysporum formae speciales complex. FEMS Microbiology Letters. 334:16-21.

Gao, L.L., Zhang, Q., Sun, X.Y., Jiang, L., Zhang, R., Sun, G.Y., Zha, Y.L., Biggs, A.R., 2013. Etiology of moldy core, core browning, and core rot of Fuji apple in China. Plant Disese. 97:510-516.

Gil, M.I., Tomas-Barberan, F.A., Hess-Pierce, B., Holcroft, D.M., Kader, A.A., 2000. Antioxidant activity of pomegranate juice and its relationship with phenolic composition and processing. Journal ofAgricultural Food Chemistry. 48:4581-4589.

Harteveld, D.O.C., Akinsanmi, O.A., Drenth, A.. 2013. Multiple Alternaria species groups are associated with leaf blotch and fruit diseases in Australia. Plant Pathology. 62:289-297.

Hewson, K., Noormohammadi, A.H., Devlin, J.M., Mardani, K., Ignjatovic, J., 2009. Rapid detection and nonsubjective characterisation of infectious bronchitis virus isolates using high-resolution melt curve analysis and a mathematical model. Archives of Virology. 154:649-660.

Hong, S.G., Cramer, R.A., Lawrence, C.B., Pryor, B.M., 2005. Alt a1 allergen homologs from Alternaria and related taxa: analysis of phylogenetic content and secondary structure. Fungal Genetics \& Biology. 42:119-129.

Kanetis, L., Testempasis, S., Goulas, V., Samuel, S., Myresiotis, C., Karaoglanidis, G., 2015. Identification and mycotoxigenic capacity of fungi associated with pre- and postharvest fruit rots of pomegranates in Greece and Cyprus. International Journal of Food Microbiology. 208:84-92.

Kou, L., Gaskins, V.L., Luo, Y., Jurick, II. W.M., 2014. First report of Alternaria tenuissima causing postharvest decay on apple fruit from cold storage in the United States. Plant Disease. 98:690.

Liew, M., Pryor, R., Palais, R., Meadows, C., Erali, M., Lyon, E., Wittwer, C., 2004. Genotyping of single- nucleotide polymorphisms by high-resolution melting of small amplicons. Clinical Chemistry. 50(7):1156-1164.

Logrieco, A., Bottalico, A., Mule, G., Moretti, A., Perrone, G., 2003.Epidemiology of toxigenic fungi and their associated mycotoxins for some Mediterranean crops. European Journal of Plant Pathology. 109:645-667.

Michailides, T.J., Morgan, D., Quist, M., Reyes, H., 2008. Infection of pomegranate by Alternaria spp. causing black heart. Phytopathology. 98:S105.

Ntasiou, P., Myresiotis, C.K., Konstantinou, S., Papadopoulou-Mourkidou, E., Karaoglanidis, G.S., 2015. Identification, characterization and mycotoxigenic ability of Alternaria spp. causing core rot of apple fruit in Greece. International Journal of Food Microbiology. 197:22-29.

Ostry, V., 2008. Alternaria mycotoxins: an overview of chemical characterization, producers, toxicity, analysis and occurrence in food stuffs. World Mycotoxin Journal. 1:175-188.

Palou, L., Taberner, V., Guardado, A., del Rio, M.A., Monstesinos-Herrero, C., 2013. Incidence and etiology of postharvest fungal diseases of pomegranate (Punica granatum cv. Mollar de Elche) in Spain. Phytopathologia Mediterranea. 52:478-489.

Reed, G.H., Wittwer, C.T., 2004. Sensitivity and specificity of single-nucleotide polymorphism scanning by high-resolution melting analysis. Clinical Chemistry. 50:1748-1754.

Shtienberg, D., 2012. Effects of host physiology on the development of core rot caused by Alternaria alternata, in Red Delicious apples. Phytopathology. 102:769-778.

Woudenberg, J.H.C., Groenewald, J.Z., Binder, M., Crous, P.W., 2013. Alternaria redefined. Studies in Mycology. 75(1):171-212.

Zambounis, A., Ganopoulos, I., Chatzidimopoulos, M., Tsaftaris, A., Madesis, P., 2015. High-resolution melting approaches towards plant fungal molecular diagnostics. Phytoparasitica. 43:265-272. 